\title{
AMSR-E melt patterns on the Southern Patagonia Icefield
}

\author{
Patricia A. MONAHAN, Joan RAMAGE \\ Earth and Environmental Science Department, Lehigh University, 1 West Packer Avenue, \\ Bethlehem, Pennsylvania 18015-3188, USA \\ E-mail: ramage@lehigh.edu
}

\begin{abstract}
Passive-microwave $37 \mathrm{GHz}$ vertically polarized $(\mathrm{V})$ brightness temperature $\left(T_{\mathbf{b}}\right)$ measurements from the Advanced Microwave Scanning Radiometer for Earth Observing System (AMSR-E) are used to monitor the extent and timing of snowmelt on the Southern Patagonia Icefield (SPI) in Chile and Argentina. Twice daily $T_{b}$ 's for 2002-08 for high-elevation (>1200 ma.s.l.) pixels exhibit a bimodal histogram, typical of snow-covered regions in Yukon, Alaskan icefields and the Greenland ice sheet. The low count between the two populations represents the $T_{\mathbf{b}}$ threshold for melt $(252 \mathrm{~K})$. This $T_{\mathbf{b}}$ value with the $\pm 18 \mathrm{~K}$ diurnal amplitude variation threshold quantifies onset and duration of the spring meltrefreeze period and is used to identify melt regimes and seasonal $T_{\mathbf{b}}$ signals. $T_{\mathbf{b}}$ histograms for pixels west of the Andean divide have a normal distribution above the melt threshold. We interpret the $T_{\mathbf{b}}$ histogram as controlled by surface moisture; the shape and position with respect to $T_{b}$ are retained with changes in both latitude and elevation, and the region is known to have a moist climate. $T_{\mathbf{b}}$ is not driven by seasonal temperature changes in the northwest sector of the icefield because the $T_{b}$ threshold is exceeded $75 \%$ of the time. For all pixels, the spring melt-refreeze period has shortened by a mean of 10 days $\mathrm{a}^{-1}$ and a mean of 16 days $^{-1}$ for pixels with bimodal distributions between 2002 and 2008.
\end{abstract}

\section{INTRODUCTION}

Passive-microwave observations make it possible to monitor remote and cloud-covered regions containing large ice masses. On the surfaces of South Greenland (Mote and others, 1993; Steffen and others, 1993; Zwally and Fiegles, 1994; Abdalati and Steffen 1995; Tedesco, 2007), coastal East Antarctica (Liu and others, 2006; Picard and others, 2007) and Alaska (Ramage and Isacks, 2003), more extensive melt and progressively earlier melt onset dates have been detected. Spatial and temporal variations have significant impacts on local and regional hydrology and glacier mass balance. On the Southern Patagonia Icefield (SPI; Fig. 1), the largest temperate ice mass in the Southern Hemisphere, covering approximately $13000 \mathrm{~km}^{2}$ (Naruse and Aniya, 1992), the melt state of the icefield as a whole has never been observed. Few mass-balance data exist for this region, leaving estimates of sea-level rise, climatic trends and hydrologic impacts practically unknown (Rignot and others, 2003). In this study of the SPI, we investigate how elevation, distance from the coast and latitude affect melt onset and the duration of the spring melt-refreeze cycle as detected by passive-microwave brightness temperature $\left(T_{\mathrm{b}}\right)$ measurements in the $37 \mathrm{GHz}$ vertically polarized $(\mathrm{V})$ channel and diurnal amplitude variations (DAV). We then use established thresholds for $37 \mathrm{~V} T_{\mathrm{b}}(252 \mathrm{~K})$ and DAV $( \pm 18 \mathrm{~K})$ to show how $T_{\mathrm{b}}$ and $\mathrm{DAV}$, indicative of melt and melt-refreeze cycles, vary over the entire icefield's surface both seasonally and interannually. The melt extent and timing influence the mass loss, so this is an important step toward observing mass variations over the entire icefield.

\section{PASSIVE-MICROWAVE-DERIVED MELT}

Passive-microwave sensors collect microwave radiance as a $T_{\mathrm{b}}$ measurement with sensitivity to the surface characteristics. On glaciers, snowmelt and refreeze processes taking place on and near the surface have dramatic effects on $T_{b}$.
Snowmelt extent and onset algorithms rely on the significant response of passive-microwave sensors to the presence of a small amount of liquid water (Chang and others, 1976; Ulaby and others, 1986). These sensors detect microwave emission from the underlying material emanating through the layers of ice and snow that make up the glacier system. Numerical models predict that within a snowpack, upwelling radiation at $37 \mathrm{GHz}$ is predominantly affected by the scattering of snow crystals (Chang and others, 1976). Snow is in an intermediate regime between optically thin emission when dry or refrozen (where the sensor collects radiation that has interacted with the entire depth of the ice, firn and snow layers) and optically thick when wet (where the sensor collects radiation only from the surface of last scattering). Volumetric scattering by dry snow and ice particles attenuates the signal, so a lower $T_{\mathrm{b}}$ is measured. The energy scattered also depends on factors such as snow density, thickness and crystal size (Chang and others, 1976). For wet snow layers, reduced volumetric scattering and increased absorption increase $T_{\mathrm{b}}$ significantly. $T_{\mathrm{b}}$ is high when the snow is wet because liquid water significantly increases the emissivity (Chang and others, 1976).

Several methods were developed for detecting melting snow and ice over Greenland and Arctic sea ice at frequencies near 19 and $37 \mathrm{GHz}$ (wavelengths of 1.58 and $0.82 \mathrm{~cm}$, respectively) utilizing passive-microwave sensors. Early studies used the $19 \mathrm{GHz} T_{\mathrm{b}}$ channel and the mean $T_{\mathrm{b}}\left(T_{\mathrm{b}}-T_{\mathrm{b} \text { mean }}\right)$ to detect wet snow (Mote and others, 1993; Zwally and Fiegles, 1994). Using a $37 \mathrm{GHz}$ horizontally polarized $(37 \mathrm{H}) T_{\mathrm{b}}$ threshold technique, Mote and Anderson (1995) investigated melt onset over Greenland. Mote (2003) then used this $37 \mathrm{H} T_{\mathrm{b}}$ threshold to quantify surface melt, using a positive degree-day approach, to investigate the interannual variability of ablation and surface mass balance over Greenland. Abdalati and Steffen $(1995,1997)$ used the $19 \mathrm{GHz}$ horizontally polarized $(19 \mathrm{H})$ channel and the $37 \mathrm{GHz}$ vertically polarized channel (37V) to define the cross-polarized gradient ratio (XPGR) or 


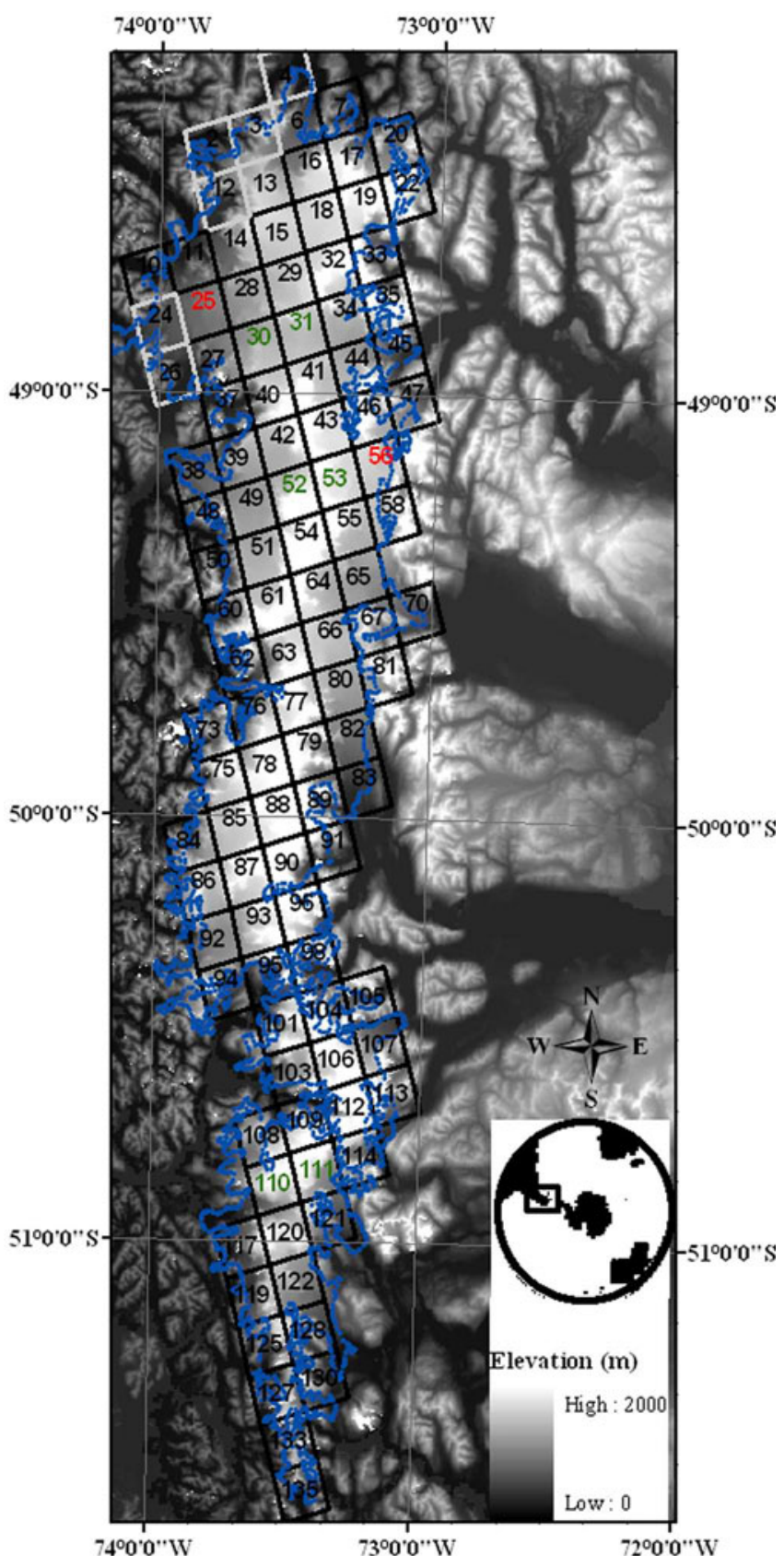

Fig. 1. SRTM DEM of the SPI with overlying $12.5 \mathrm{~km} \times 12.5 \mathrm{~km}$ Equal-Area Scalable Earth Grid (EASE-Grid) pixel classification. The location within the Southern Hemisphere is shown in the inset. Pixel codes are labeled in each gridcell. Pixels 25 (mean elevation 569 ma.s.l.) and 56 (mean elevation 1452 ma.s.l.) (red) are shown in Figure 3. Pixels 30, 31, 52, 53, 110 and 111 (green) are discussed in the text and in Table 2, and pixels 2, 3, 4, 12, 24 and 26 (grey outline) are discussed in the text and exhibit a low-contrast signal. The blue line is the approximate outline of the ice edge (courtesy of G. Casassa).

$\left(T_{\mathrm{b}(19 \mathrm{H})}-T_{\mathrm{b}(37 \mathrm{~V})}\right) /\left(T_{\mathrm{b}(19 \mathrm{H})}+T_{\mathrm{b}(37 \mathrm{~V})}\right)$. Steffen and others (1993) used the normalized gradient ratio, $\left(T_{\mathrm{b}(19 \mathrm{H})}-T_{\mathrm{b}(37 \mathrm{H})}\right) /$ $\left(T_{\mathrm{b}(19 \mathrm{H})}+T_{\mathrm{b}(37 \mathrm{H})}\right)$, to obtain a wet snow threshold by comparing satellite data and ground measurements. Drobot and Anderson (2001) also developed the advanced horizontal range algorithm (AHRA), which uses temporal variations in $19 \mathrm{H}$ and $37 \mathrm{H}$ to measure the spatial and temporal variations of snowmelt onset over sea ice from 1979 to 1998.
On the glaciers of southeast Alaska, a new approach for detecting melting snow was proposed by Ramage and Isacks (2002), using the difference between the ascending and descending $T_{\mathrm{b}}$ collected via passive-microwave sensor, the Special Sensor Microwave/Imager (SSM/I). This approach uses two co-occurring thresholds, the $37 \mathrm{~V} T_{\mathrm{b}}$ measurements of $246 \mathrm{~K}$ and a diel $T_{\mathrm{b}}$ contrast (DAV) of $\pm 10 \mathrm{~K}$, differentiating a frozen snow surface from a melting surface to determine the melt onset date (Ramage and Isacks, 2002). Ramage and Isacks (2003) corroborated this methodology based on predominately glacier-fed discharge records for a period overlapping the satellite record. Tedesco (2007) then used this technique to map the areal extent of melting snow over Greenland using 19V and 37V $T_{\mathrm{b}}$ SSM/I channels.

Apgar and others (2007) refined the $T_{\mathrm{b}}$ and DAV approach for the Advanced Microwave Scanning Radiometer for Earth Observing System (AMSR-E) sensor to retrieve snowmelt onset timing and transition duration in the upper Yukon River basin (Apgar and others, 2007; Ramage and others, 2007). Apgar and others used in situ measurements of temperature taken at 2 hour intervals using automatic data loggers (HOBO, Pro Series) and wetness percent from a snow capacitance probe during AMSR-E overpass to determine thresholds. Melt onset constitutes the first occurrence where one daily $T_{\mathrm{b}}$ is greater than $252 \mathrm{~K}$ and the DAV are greater than $\pm 18 \mathrm{~K}$ in the $37 \mathrm{~V}$ channel (Apgar and others, 2007). This algorithm is applied to the SPI.

\section{STUDY SITE}

The SPI is located in the southern Andes, extending from $48^{\circ} 15^{\prime} \mathrm{S}$ to $51^{\circ} 35^{\prime} \mathrm{S}$ and from $72^{\circ} 30^{\prime} \mathrm{W}$ to $74^{\circ} 30^{\prime} \mathrm{W}$ (Aniya and others, 1997; De Angelis and others, 2007). It contains 48 temperate outlet glaciers (Aniya and others, 1997), with most glaciers flowing eastwards. All of these glaciers except Frias Glacier and Bravo Glacier calve into bodies of water (Aniya and others, 1997). There is a scarcity of climatological stations on, and adjacent to, the SPI (Rasmussen and others, 2007). The SPI is influenced by both Antarctic and mid-latitude atmospheric circulation patterns and a diversity of climatic environments (Warren and Sugden, 1993). Prevailing westerly winds from the Pacific Ocean combined with the steep Andean terrain generate high precipitation on the SPI's western front, with accumulation diminishing towards the east (Rivera and Casassa, 2004). Thus, mass balance on the west is dominated by winter snow accumulation while the east undergoes significant summer ablation. Both the western and eastern regions of the SPI experience high mass turnover rates with significant interannual variability in accumulation and ablation (Bamber and Rivera, 2007).

Research efforts involving the SPI have increased substantially during the last decade, but many glaciological variables, especially mass balance, are still poorly understood (De Angelis and others, 2007). Aniya and others (1997) investigated terminus variations for the 48 outlet glaciers of the SPI based on maps, aerial photographs and satellite imagery. Their study demonstrates that the termini of many glaciers in the region exhibit a general pattern of recession, but differences are evident from one glacier to another. Rignot and others (2003) used a digital elevation model (DEM)-differencing approach to achieve the first regional mass-balance study. From 1975 to 2000, glacier loss yielded $0.042 \pm 0.002 \mathrm{~mm} \mathrm{a}^{-1}$ sea-level equivalent (SLE), with a 
higher rate of $0.105 \pm 0.011 \mathrm{~mm} \mathrm{a}^{-1}$ SLE during the 19952000 period (Rignot and others, 2003). Another recent study estimates the combined contribution of the Northern and Southern Patagonia Icefields to sea-level rise using forward modeling and 5 years of Gravity Recovery and Climate Experiment (GRACE) data (Chen and others, 2007). After correcting for glacial isostatic adjustment and hydrological effects, Chen and others (2007) estimated a contribution of $0.078 \pm 0.031 \mathrm{~mm} \mathrm{a}^{-1} \mathrm{SLE}$, comparable to the rates obtained by Rignot and others (2003). We use twice daily passivemicrowave measurements covering the entire icefield to generate a spatially complete and temporally dynamic highresolution reconstruction of melt dynamics on the icefield from 2002 to 2008. We also investigate which regions are dominated by a seasonal $T_{\mathrm{b}}$ distribution and those regions that experience interspersed wet snow, frozen snow or melting and refreezing snow throughout the year.

\section{DATA}

This investigation analyzes data from the AMSR-E, a sixfrequency $(6.925,10.650,18.700,23.800,36.500$ and 89.000 GHz) dual polarized total-power conically scanning passive-microwave radiometer on board NASA's Aqua satellite (Kawanishi and others, 2003). We focus on austral hydrological years (Table 1) from 2002 to 2008. Three datasets were acquired: AMSR-E/Aqua Level-2A global swath spatially resampled $T_{\mathrm{b}}$ (http://nsidc.org/data/ae_I2a. html); a 3 arcsec (90 $\mathrm{m}$ resolution) DEM image from the Shuttle Radar Topography Mission (SRTM) (Farr and Kobrick, 2000); and drainage basin delineations used to infer the Andean topographic divide (http://eros.usgs.gov/products/ elevation/gtopo30/hydro/sa_basins.html). Using Geographic Information System (GIS) software, multiple $3 \operatorname{arcsec}(90 \mathrm{~m})$ SRTM DEMs were acquired and joined to produce the SPI data used in this investigation. The SPI extent was determined by placing the Equal-Area Scalable Earth Grid (EASE-Grid) over the SRTM DEM. Glacier boundaries were double-checked with the few available cloud-free Advanced Spaceborne Thermal Emission and Reflection Radiometer (ASTER) images and an ice-margin delineation (courtesy of G. Casassa). A total of 107 high-resolution $(12.5 \mathrm{~km} \times 12.5 \mathrm{~km})$ EASE-Grid pixels cover the SPI (Fig. 1). Using GIS grid overlay software, each pixel was individually clipped out of the SRTM DEM to extract spatial statistics. The elevation histogram and mean, minimum and maximum elevations were used to characterize each pixel.

AMSR-E L2A global swath spatially resampled $T_{\mathrm{b}}$ measurements for 2002-08 were acquired free of cost from the Warehouse Inventory Search Tool (WIST) website (http:// wist.echo.nasa.gov/ wist/api/imswelcome) provided by NASA. The US National Snow and Ice Data Center (NSIDC) provides an AMSR-E swath-to-grid toolkit (AS2GT) (http:// nsidc.org/data/tools/pmsdt/as2gt.html) with software tools to subset and grid L2A AMSR-E swath data at any spatial resolution and map projection. AMSR-E data are interpolated to the output EASE-Grid, Southern Hemisphere projection, from swath space using an inverse-distance squared method. The EASE-Grid has a nominal $12.5 \mathrm{~km}$ $\times 12.5 \mathrm{~km}$ grid spacing. The instantaneous field-of-view dimensions are approximately $27 \mathrm{~km} \times 16 \mathrm{~km}$ at $37 \mathrm{GHz}$ (mean spatial resolution of $12 \mathrm{~km}$ ). EASE-Grid tools are provided by the NSIDC (http://nsidc.org/data/ease/ tools.html). The NSIDC also provides Interactive Data
Table 1. Date ranges for austral hydrologic seasons 2002-08

\begin{tabular}{lcc}
\hline Date range & Hydrologic season & Days \\
\hline 1 July-30 September & Winter & 91 \\
1 October-31 December & Spring & 91 \\
1 January-1 April & Summer & $91(92$ in 2004) \\
2 April-30 June & Fall & 92 \\
\hline
\end{tabular}

Language (IDL) routines and map projections for geolocation and conversion tools to use with EASE-Grid datasets.

AMSR-E L2A data are in Hierarchical Data Format (HDF). The NSIDC tools AMSR-E_L2A_togs and the gsgrid (Southern Hemisphere high-resolution grid) procedures were used to process the raw AMSR-E data from HDF format to gridded $T_{\mathrm{b}}$. Data were gridded to $12.5 \mathrm{~km} \times 12.5 \mathrm{~km}$ EASE-Grid AMSR-E files for $T_{\mathrm{b}}$ in 10.7, 18.7, 23.8, 36.5 and $89.0 \mathrm{GHz}$ for both horizontal and vertical polarizations containing the time and date of satellite acquisition. An IDL program then read in all the gzipped EASE-Grid AMSR-E output files and extracted $T_{\mathrm{b}}$ in all channels and polarizations for the 107 high-resolution pixels covering the SPI. This program also wrote text files for each pixel containing all $T_{\mathrm{b}}$ measurements ordered sequentially for a year and acquisition time in decimal days. Using the IDL environment, both $T_{\mathrm{b}}$ and DAV (the difference between the daily maximum and minimum $T_{\mathrm{b}}$ ) structures were created for all 107 pixels and tagged according to channel, acquisition time and the spatial statistics extracted from the SRTM DEM.

\section{METHODS \\ Quantifying melt onset, transition end and spring
melt-refreeze duration}

$37 \mathrm{~V} T_{\mathrm{b}}$ and DAV data are used to capture the onset and duration of melt-refreeze cycles and the onset of sustained melting within each austral hydrologic year from 2002 to 2008. The first step was to determine whether existing thresholds were applicable to this environment. AMSR-E $T_{\mathrm{b}}$ and DAV thresholds of $252 \mathrm{~K}$ and $\pm 18 \mathrm{~K}$ in the $37 \mathrm{~V}$ channel appear to be robust on the SPI based on the $T_{\mathrm{b}}$ distribution (histogram plots) of all snow-covered high-elevation pixels (Fig. 2). The $37 \mathrm{~V} 252 \mathrm{~K}$ threshold corresponds to the low count separating the two populations of lower $T_{\mathrm{b}}$ values of a frozen surface and a higher $T_{\mathrm{b}}$ value of a wet surface. The DAV capture the diurnal fluctuation of liquid water content at the spring melt onset. At night a refreezing snow surface forms larger grains, which increase volumetric scattering, and tends to have a lower $T_{\mathrm{b}}$ than fresh snow (Ramage, 2001). The $T_{\mathrm{b}}$ and DAV thresholds detect the presence of liquid water, and a large diurnal $T_{\mathrm{b}}$ range indicates the process of melting and refreezing.

The AMSR-E $T_{\mathrm{b}}$ signature is sensitive, and short-term variability makes it difficult to automate transition end. For instance, within a prolonged melt period, there are notable instances where $T_{\mathrm{b}}$ fluctuates similar to the transition period, but for a brief duration. This synoptic variability complicates pinpointing the correct transition end date. In this investigation, rather than using transition end, 'sustained melt' is defined because the influence of this synoptic variability on melt has yet to be determined. Sustained melting begins 


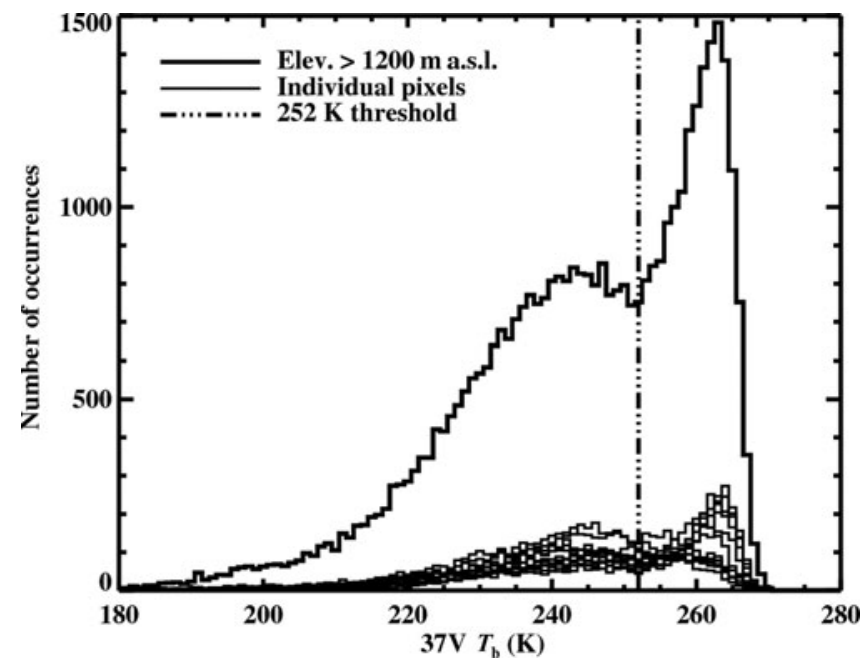

Fig. 2. Frequency histograms of twice daily $37 \mathrm{~V} T_{\mathrm{b}}$ measurements for 2002-08 for all pixels (thick black curve) and individual pixels with minimum elevations $>1200$ ma.s.l. (thin black curves). Histogram shapes are bimodal, typical of other large ice masses such as the icefields of Alaska and the Greenland ice sheet. The left distribution and right distributions distinguish $T_{\mathrm{b}}$ from dry and refrozen snow $(180-252 \mathrm{~K})$ vs wet snow $(>252 \mathrm{~K})$. The $T_{\mathrm{b}}$ that separates these two conditions is the $T_{\mathrm{b}}$ threshold $(252 \mathrm{~K})$. when $T_{\mathrm{b} \text { min }}$ exceeds $252 \mathrm{~K}$ on 6 out of 7 consecutive days. The first day of the sequence is the sustained melt onset date. The spring melt-refreeze duration is comparable to the transition period (Apgar and others, 2007), but is calculated as the number of days between the melt onset and sustained melt onset.

Figure 3 illustrates when 37V $T_{\mathrm{b}}$ and DAV thresholds indicate melt onset, transition duration and transition end for pixels 25 (mean elevation 569 ma.s.l.) and 56 (mean elevation 1452 ma.s.l.) during the 2007/08 hydrologic year (begins on 1 July in the Southern Hemisphere). Melt onset (solid line) occurs in the $37 \mathrm{~V}$ channel once $T_{\mathrm{b} \_ \text {max }}$ is greater than $252 \mathrm{~K}$ and the DAV are greater than $\pm 18 \mathrm{~K}$. After melt onset, the transition period is when $T_{\mathrm{b}}$ and DAV fluctuate as the surface undergoes diel (vertical) melting and refreezing. The transition end date occurs when there is consistent surface melting. This is defined as when $T_{b \_m i n}$ remains above the $252 \mathrm{~K}$ threshold for a consecutive period of time ( 6 days in this study; dashed line). The $T_{\mathrm{b}}$ signature re-enters this diel fluctuation cycle again as temperatures drop in austral autumn (Fig. 3).

\section{Quantifying melt extent}

Each pixel on the icefield was classified according to its $37 \mathrm{~V}$ $T_{\mathrm{b}}$ histogram distribution. Two general categories are
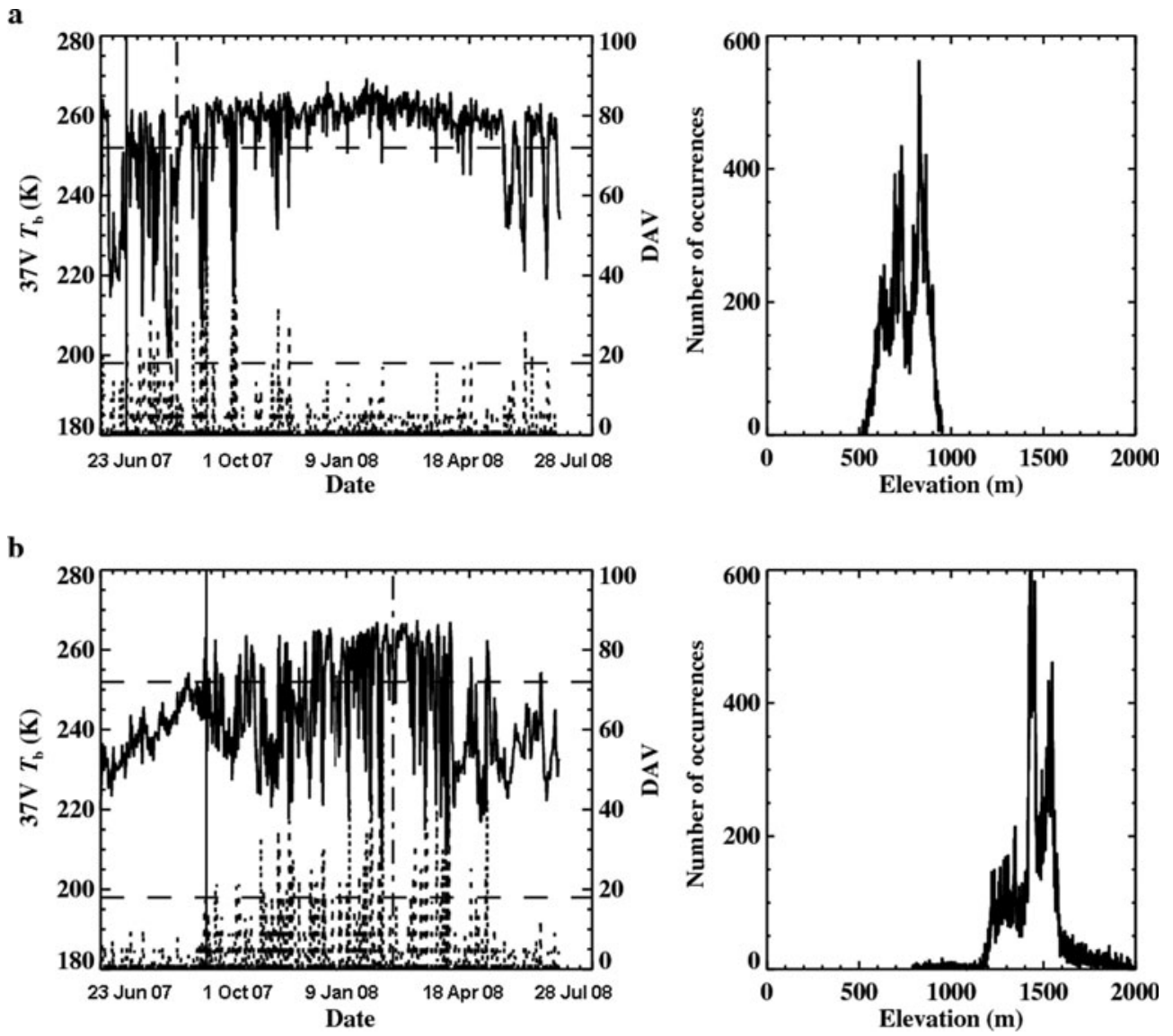

Fig. 3. 2007/08 hydrologic year 37V $T_{\mathrm{b}}$ (black curve) and DAV (dashed curve) time series for pixels with different mean elevations on the SPI. (a) Low-elevation pixel 25 (mean elevation $569 \mathrm{~m}$ a.s.I.) and (b) higher-elevation pixel 56 (mean elevation $1452 \mathrm{~m}$ a.s. I.). A histogram of elevations $(\mathrm{m})$ extracted from the 3 arcsec SRTM DEM for each pixel is shown next to the time series. After austral winter temperatures begin to rise, when $T_{\mathrm{b}}>252 \mathrm{~K}$ and $\mathrm{DAV}> \pm 18 \mathrm{~K}$, it signifies the melt onset date (solid line) where there is daytime melting and night-time refreezing. This period is referred to as the transition period. As temperatures increase, daily fluctuations cease and daytime $T_{\mathrm{b}}$ remains above $252 \mathrm{~K}$ for a consecutive period of time, indicating the end of the transition period (dashed line). In this example, the timing and duration of melt are affected by elevation. Pixel 25 experiences an earlier melt onset and a shorter transition period relative to pixel 56. 


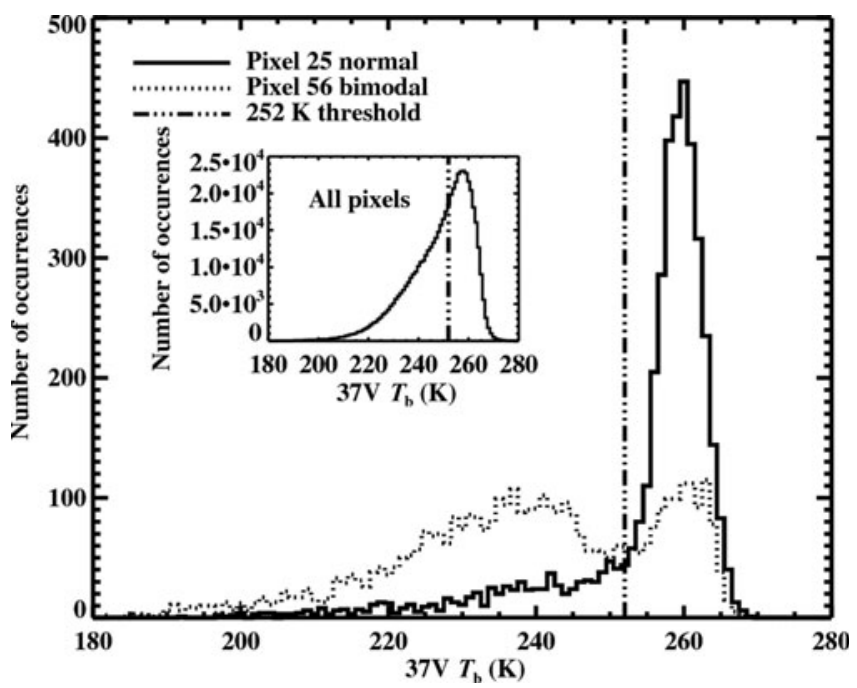

Fig. 4. Frequency histograms of twice daily $37 \mathrm{~V} T_{\mathrm{b}}$ measurements for pixels 25 and 56 from 2002 to 2008. Pixel 56 has a bimodal distribution. The left and right distributions distinguish $T_{\mathrm{b}}$ between dry and refrozen snow and wet snow. The $T_{\mathrm{b}}$ that separates these two conditions is the $T_{\mathrm{b}}$ threshold $(252 \mathrm{~K})$. Pixel 25 and the inset showing a histogram of all $37 \mathrm{~V} T_{\mathrm{b}}$ measurements from all of the SPI pixels for this period display an asymmetrical distribution that is skewed to the right and peaks above the $T_{\mathrm{b}}$ threshold.

defined for the SPI based on their histograms. The first type includes pixels with a bimodal distribution, with the established $252 \mathrm{~K}$ melt threshold constituting the low-count $T_{\mathrm{b}}$ between the two large populations of high or low $T_{\mathrm{b}}$. The second type includes pixels with an asymmetrical distribution that is skewed to the right and peaks $4-8 \mathrm{~K}$ above the established threshold (Fig. 4). Four types of melt regimes can be derived from histogram shapes: (1) a bimodal distribution with a peak at low $T_{\mathrm{b}}$ (Fig. 5a); (2) an equal bimodal distribution (Fig. 5b); (3) a bimodal distribution with a peak at high $T_{\mathrm{b}}$ (Fig. 5c); and (4) an asymmetrical distribution (Fig. $5 \mathrm{~d}$ ). The bimodal histogram with a peak at low $T_{\mathrm{b}}$ indicates a longer period spent frozen relative to time spent wet. Conversely, the bimodal histogram with a peak at high $T_{\mathrm{b}}$ indicates a longer period spent melting and wet relative to time spent dry. The asymmetrical distribution indicates that the surface is wet and melting well over $50 \%$ of the time.
The distribution of histogram types is mapped for each pixel over the SPI (Fig. 6).

The spatial distribution of seasonal variations in $T_{\mathrm{b}}$ distinguishes regions with high-contrast from those with low-contrast (typically moisture-dominated) surface characteristics. We mapped the percentage time a pixel is above the $252 \mathrm{~K}$ threshold per season and year as a way to discriminate high- and low-contrast regions. Low-contrast regions indicate regions of high surface moisture which results from maritime air masses, and high-contrast regions are dominated by a more continental signal (Fig. 7).

\section{RESULTS}

\section{Melt onset}

Annual time series of $T_{\mathrm{b}}$ and DAV show a seasonal $T_{\mathrm{b}}$ cycle with short-term variability events occurring over the whole icefield. Later we distinguish between areas that are more dominated by low-contrast seasonal conditions from areas with high-contrast seasonal temperature fluctuations. Other regions experience sustained periods of high DAV fluctuations, especially in the high-elevation areas. We look in more detail at pairs of pixels at different mean elevations on either side of the divide, in the northern, middle and southern parts of the icefield.

Melt onset, sustained melt onset and the spring meltrefreeze duration vary for these six pixels (Table 2). Melt onset is typically in late austral winter or early spring beginning in July for pixels north of $48^{\circ} 50^{\prime} \mathrm{S}$, with mean elevations below $1500 \mathrm{~m}$ and located west of the divide. Here the spring melt-refreeze cycle lasts 57 days (except pixel 30). For pixel 30, sustained melt onset starts on 26 July. The comparable pixel east of the divide melts on 15 September with a melt-refreeze duration of 31 days. In the middle of the icefield, melt onset on the west is 7 days earlier relative to the east, whereas in the south it is 75 days earlier in the west. The last wave of melt onset occurs in November for pixels east of the divide and distant from the equator. Sustained melt onset south of $48^{\circ} 50^{\prime} \mathrm{S}$ occurs in December and January, with melt onset occurring 25-35 days earlier for pixels west of the divide. Some pixels do not fit this model, typically those with mean elevations greater than $1500 \mathrm{~m}$ and located to the east of the divide. These pixels never stop the diel melt-refreeze
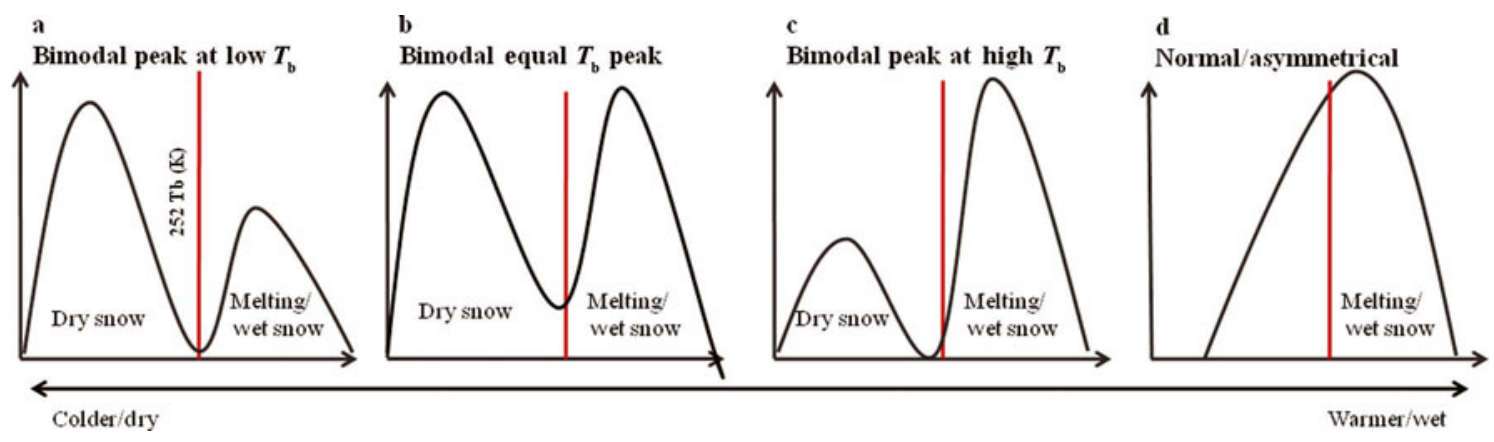

Fig. 5. 37V $T_{\mathrm{b}}$ histograms differentiate four types of melt regimes over the SPI. The $37 \mathrm{~V} T_{\mathrm{b}}$ threshold $(252 \mathrm{~K}$ ) is shown as a vertical line. (a) The bimodal peak at a low $T_{\mathrm{b}}$ value indicates that the snow is dry three-quarters of the time. (b) An equal bimodal distribution can be interpreted as the left distribution being $T_{\mathrm{b}}$ of dry snow in the winter and the right distribution being $T_{\mathrm{b}}$ of melting snow in the summer. (c) The bimodal histogram with a peak at high $T_{\mathrm{b}}$ indicates a longer period of time melting and wet relative to time spent dry. (d) The normal distribution peaks near or above the $T_{\mathrm{b}}$ threshold and indicates that the surface is wet and melting for most of the time. 


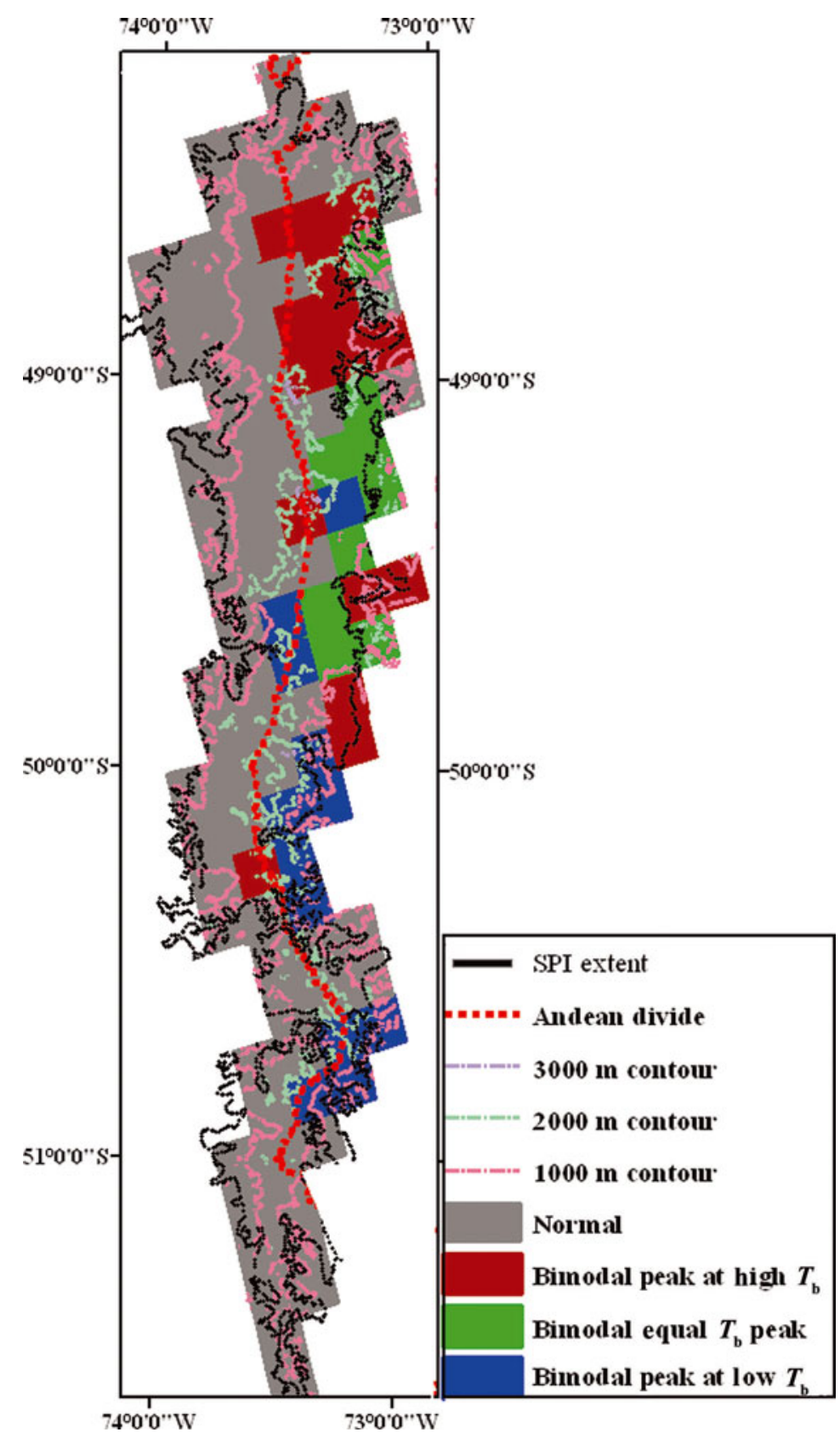

Fig. 6. Map showing distribution of melt regimes based on histogram type across the SPI. Bimodal distributions with a peak at high $T_{\mathrm{b}}$ occur in the northeast (red). Bimodal distributions with equal peaks are in the northeast and middle sector on pixels with a mean elevation below 1500 ma.s.l. (green). Bimodal distributions with a peak at low $T_{\mathrm{b}}$ are in the middle and southern sector on pixels with mean elevations $>1500 \mathrm{~m}$ a.s.l. (blue). The normal and asymmetrical shape is directly west of the divide and retains this shape with varying latitude and mean elevation (gray). The black line is the approximate outline of the ice edge.

Table 2. Pixel characteristics for selected pixels discussed in the text. See Figure 1 for the locations of these pixels. All dates listed are for the austral hydrologic year 2007/08

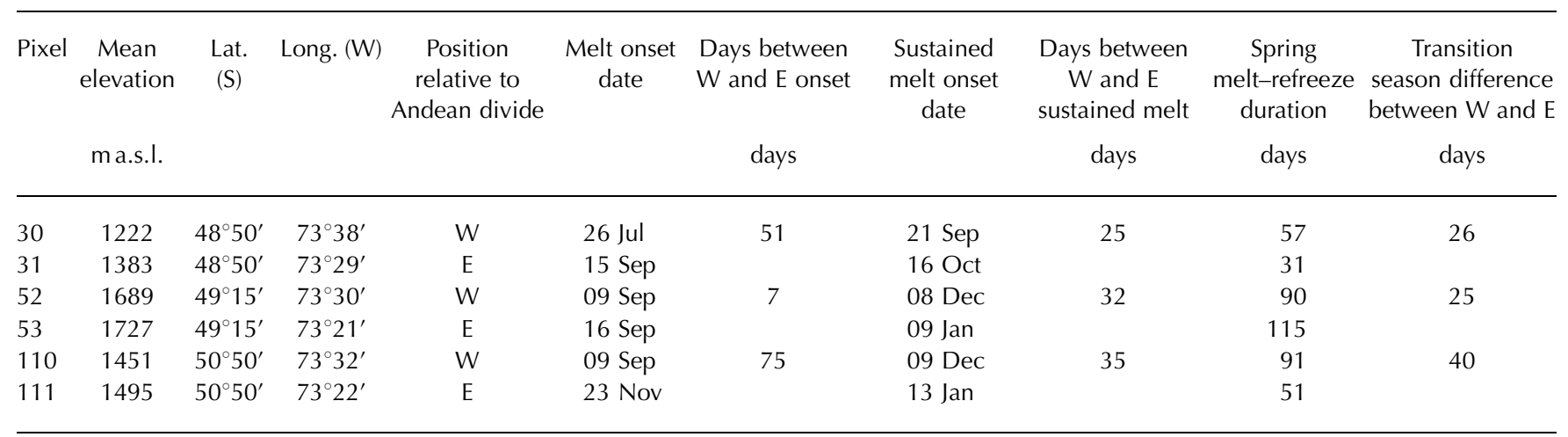



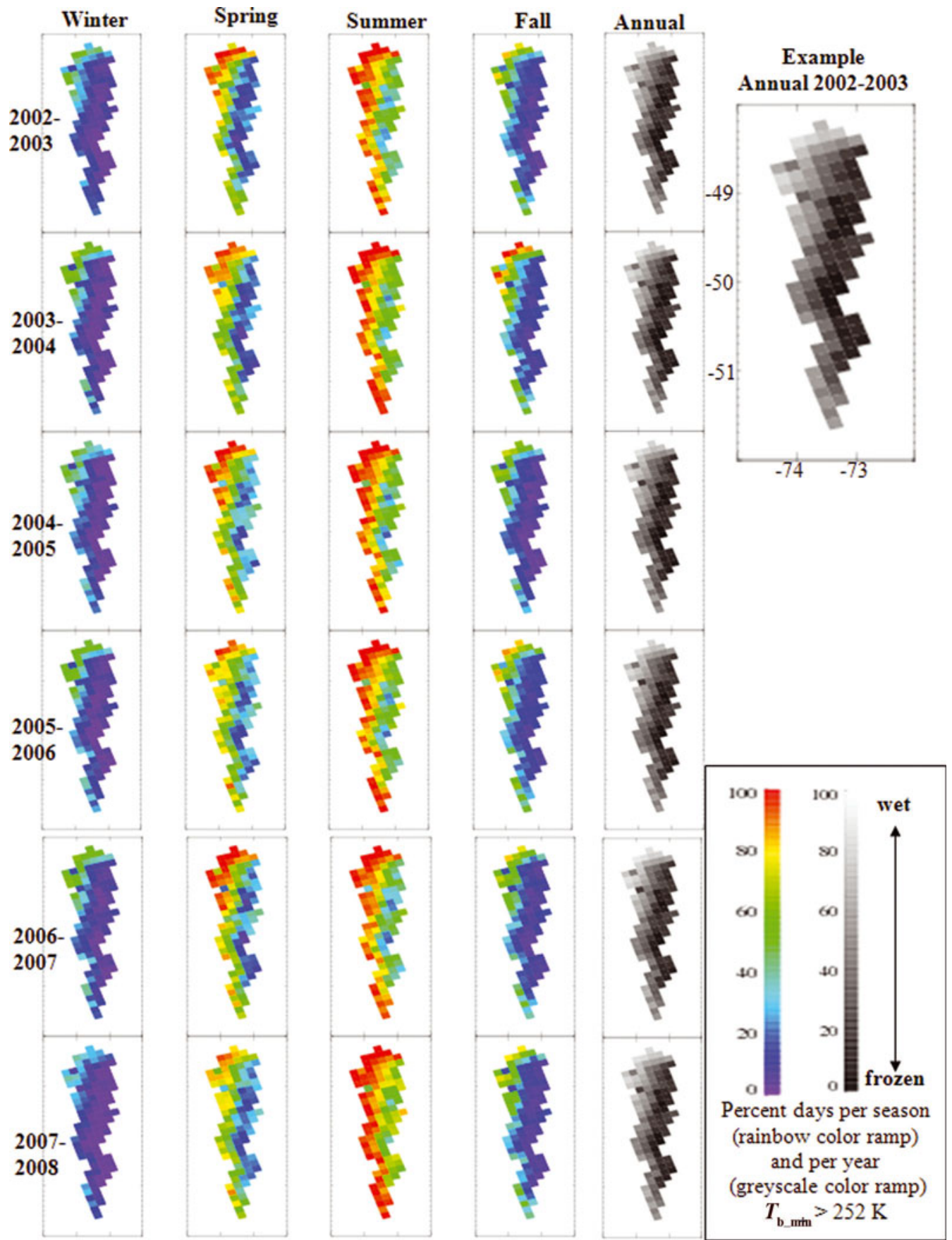

Fig. 7. Seasonal and interannual distributions of melt throughout the SPI for hydrologic years 2002-07. The melt maps for each season are based on the percentage of time both the daily $T_{\mathrm{b} \_ \text {max }}$ and $T_{\mathrm{b} \_ \text {min }}$ are greater than the $37 \mathrm{~V} T_{\mathrm{b}}$ threshold ( $0 \%$ (blue) to $100 \%$ (red)) for each season within the austral hydrologic years from 2002 to 2007 . The annual maps are calculated based on the percentage of time both the daily $T_{\mathrm{b} \_ \text {max }}$ and $T_{\mathrm{b} \_ \text {min }}$ are greater than the $37 \mathrm{~V} T_{\mathrm{b}}$ threshold (0\% (black) to $100 \%$ (white)) for each year and thus also have a low DAV. Seasonally and annually there are pixels with a dominant signature characterizing melting (includes wetness due to rain), frozen, or melting and refreezing. Depending which is dominant, the pixel is considered low-contrast, where the $T_{\mathrm{b}}$ signal is primarily influenced by maritime air masses $\left(T_{\mathrm{b} \_\min }>252 \mathrm{~K} 75 \%\right.$ of the time), or high-contrast, where the $T_{\mathrm{b}}$ 's show that surface moisture is lower and the region has a more continental climate.

process and express the transition period for the whole austral summer until April.

\section{Melt extent}

For the SPI, $T_{\mathrm{b}}$ histogram shapes fall into two main classes: those with bimodal distributions peaking at low, equal or high $T_{\mathrm{b}}$ and those skewed to the right with an asymmetrical peak $4-8 \mathrm{~K}$ above the $252 \mathrm{~K} T_{\mathrm{b}}$ threshold. The characteristic bimodal shape is typical of pixels east of the Andean divide. Figure 6 shows the locations of these different types of $T_{\mathrm{b}}$ distributions on the SPI. Bimodal distributions with a peak at high $T_{\mathrm{b}}$ occur in the northeast and southeast. Bimodal distributions with a peak at low $T_{\mathrm{b}}$ are in the middle sector on pixels with mean elevations above $1500 \mathrm{~m}$. Bimodal distributions with equal peaks are in the northeast on pixels with a mean elevation below $1500 \mathrm{~m}$. West of the topographic divide (dotted line in Fig. 6), histograms remain asymmetrical and skewed to the right. They preserve this shape with increasing latitude and elevation. 
For all pixels, distance from the coast (windward or leeward position relative to the divide) plays a critical role in $37 \mathrm{~V} T_{\mathrm{b}}$ histogram distribution shape. Latitudinal variations have no effect on the melt signature on the windward side of the SPI, from $48^{\circ} \mathrm{S}$ to $51^{\circ} \mathrm{S}$, spanning a distance of $\sim 350 \mathrm{~km}$. On the leeward side, the $T_{\mathrm{b}}$ histograms change with increasing latitude and elevation. For pixels with a mean elevation above $1500 \mathrm{~m}$, the bimodal distribution peaks at lower $T_{\mathrm{b}}$. The bimodal distribution peaks at higher $T_{\mathrm{b}}$ values for pixels close to the equator and it shifts to a peak at lower $T_{\mathrm{b}}$ values for those pixels that are more distant (southerly).

The percentage time above the melt threshold for each hydrologic season within each hydrologic year, and for each year, is used to determine the distribution of melt (Fig. 7). In winter the majority of pixels have daily $T_{\mathrm{b}}$ below $252 \mathrm{~K}$ throughout the season except in the northwest, where a few pixels spend $20-50 \%$ of the time melting. In spring, melt days increase in number on the windward side of the Andes and the leeward surface remains frozen. The majority of pixels throughout the icefield melt during summer. The distribution of melt diminishes dramatically from summer to fall. More pixels are below $252 \mathrm{~K}$ in fall relative to spring. These maps of total melt show very little regional seasonal or interannual variability.

The annual maps show that the windward side has a greater percentage of melt days than the leeward side. In the northern SPI, pixels 2, 3, 4, 12, 24 and 26 spend over $75 \%$ of the time above the $T_{\mathrm{b}}$ threshold. For these pixels, $T_{\mathrm{b}}$ is not driven by temperature changes and we interpret them as low-contrast pixels dominated by maritime conditions. The remaining pixels show a high-contrast $T_{\mathrm{b}}$ signal where surface moisture is lower and the region has a more continental climate. East of the divide, between $-48.8^{\circ} \mathrm{S}$ and $-50.8^{\circ} \mathrm{S}$ and at elevations above $1500 \mathrm{~m}$, transition and non-melt days occur interspersed throughout the hydrologic year.

The variation of melt timing for the pixels least affected by maritime climate is summarized for the period of record. For pixels east of the divide, $T_{\mathrm{b}}$ histograms have a bimodal distribution, with the $252 \mathrm{~K}$ melt threshold constituting the low-count $T_{\mathrm{b}}$ between the two large populations of high and low $T_{\mathrm{b}}$. For these areas, temperature is the dominant massbalance control and they lack frequent rainfall. Figure 8a shows the mean spring melt-refreeze duration for all pixels and for pixels with bimodal distributions for hydrologic years 2002-07. For all pixels, the mean spring melt-refreeze period has changed by -10 days $\mathrm{a}^{-1}$ and it is -16 days $^{-1}$ for pixels with bimodal distributions. The mean spring meltrefreeze period has changed by $-22,-15$ and -13 days $a^{-1}$ for those pixels with bimodal distribution with peaks at low $T_{\mathrm{b}}$, equal $T_{\mathrm{b}}$ and high $T_{\mathrm{b}}$, respectively. Figure $8 \mathrm{~b}$ shows the spring melt-refreeze duration for all pixels and years. Interannual variability exists and a decreasing duration of the spring melt-refreeze period is apparent from hydrologic years 2002-07.

\section{DISCUSSION}

Quantifying the annual pattern of $37 \mathrm{~V} T_{\mathrm{b}}$ observations, indicative of surface moisture, shows where $T_{\mathrm{b}}$ 's are driven by seasonal temperature changes. This facilitates spatially distributed interpretations of surface melt and melt-refreeze cycles in a region of high climatic and topographic diversity such as the SPI. The AMSR-E signal is seasonal east of the divide, which makes it possible to interpret melt timing, extent and duration. In this region, melt starts in midSeptember; regions with higher mean elevations that are also farther from the equator start to melt in December. West of the divide, melt and sustained melt onset always occur significantly earlier relative to the east. In the northwest region of the icefield, melt onset occurs in July, with later melt onset dates occurring in early September. It is worth noting that the observations of melt and sustained melt onset west of the divide may be complicated by accumulation rates and rain-induced surface moisture. Pixels west of the divide all have $37 \mathrm{~V} T_{\mathrm{b}}$ histograms with asymmetrical distributions. High precipitation rates on the windward side of the SPI most likely contribute to this shape. Mote and Anderson (1995) simulated $37 \mathrm{H} \mathrm{T}_{\mathrm{b}}$ and April emissivity over the Greenland ice sheet and found higher emissions in the southeast where accumulation rates are high. Rainwater in the surface will also increase the surface emissivity and hence $T_{\mathrm{b}}$. The stability of this asymmetrical shape with changes in latitude and elevation supports this conclusion. On the southern sector of the icefield, $T_{\mathrm{b}}$ and DAV fluctuations are of lesser magnitude, perhaps because this region has a lower mean elevation and is more homogeneous. Mapping ice- and snow-covered regions based on their histogram shape, either asymmetrical high- $T_{\mathrm{b}}$ bimodal, low- $T_{\mathrm{b}}$ bimodal or equal- $T_{\mathrm{b}}$ bimodal, is useful for accurate interpretations of melt timing and duration trends.

The melt signature can be tested for its applicability to predict melt onset and runoff timing. Ramage and Isacks (2003) and Kopczynski and others (2008) showed the predictive capability of the transition end date for determining peak runoff timing in streams fed predominantly by glaciers in Alaska. During the spring transition period, daily melting and refreezing occurs and melt is retained within the glacial system. It is not until constant melting starts, as indicated by $T_{\mathrm{b}}>252 \mathrm{~K}$ and a low DAV for a consecutive period of time, that melt permeates and runoff is detected down-glacier. A strong relationship is found in Alaska between the end of the melt-refreeze cycle and snowmelt flood timing (Kopczynski and others, 2008). If a significant relationship between the timing of AMSR-E-derived melt and rises in streamflow exists, subtracting the lag time will show the $T_{\mathrm{b}}$ signal history up to meltwater release. Ultimately, this tool will help us determine the degree to which storms and melt events influence runoff.

Surface melt extent and timing are intimately tied to internal dynamics within temperate glacial systems. Figure 8 shows the spring surface melt-refreeze cycle becoming shorter from 2002 to 2008 for regions that have temperature as their dominant control on melt. On the Greenland ice sheet, Zwally and others (2002) found ice acceleration when the duration of surface melting increased. Changes in the spring melt-refreeze period will affect ice movement via changes in meltwater storage, and the timing and volume of runoff to streams that are predominantly fed by the SPI.

\section{CONCLUSIONS}

Daily AMSR-E brightness temperatures over the SPI show coherent $T_{\mathrm{b}}$ and DAV on an annual basis. Changes in latitude, elevation and location relative to the spine of melt on the Andes affect the timing and characteristics of melt. Melt onset is highly variable for different regions and elevations throughout the icefield. Melt onset occurs in 


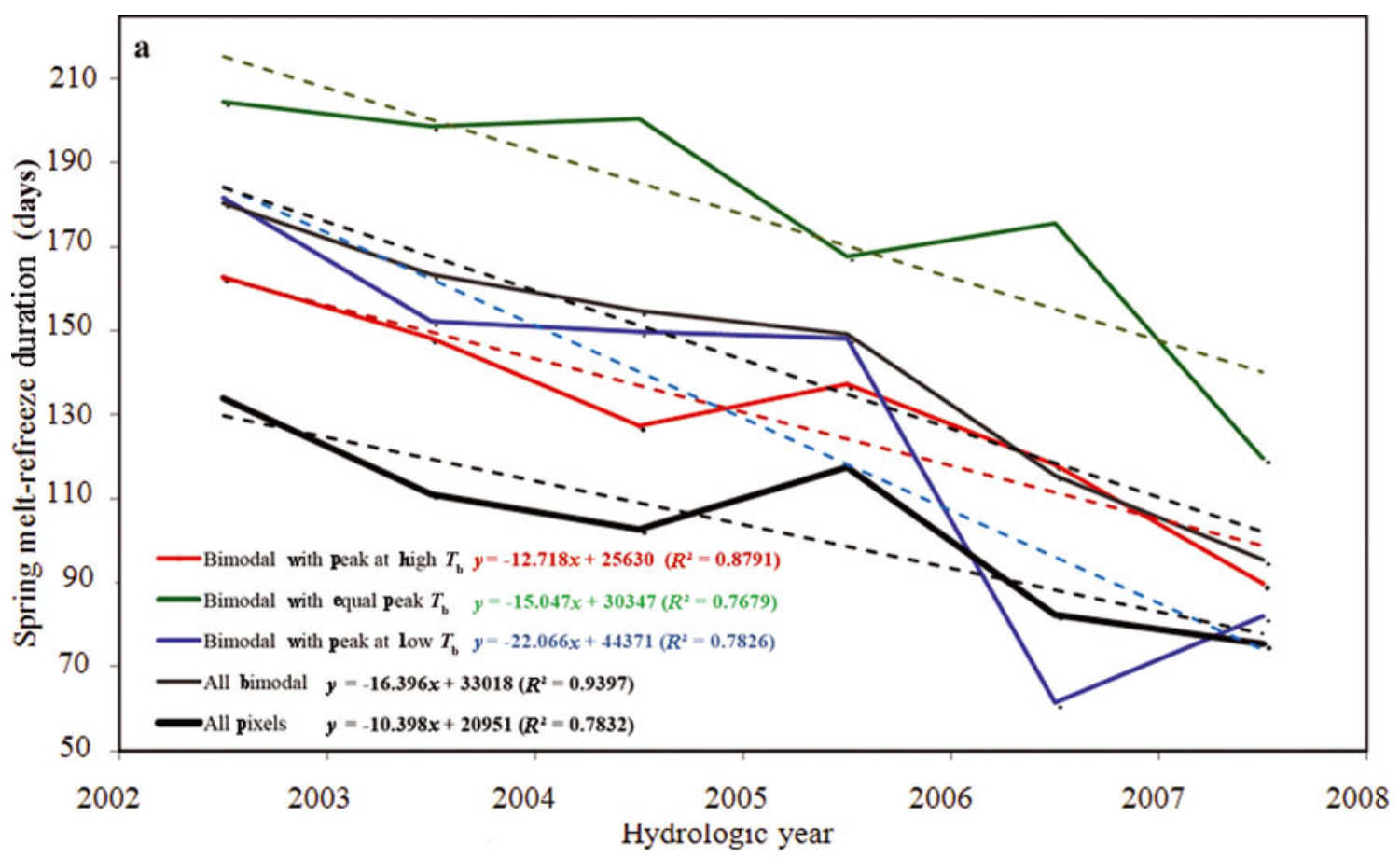

b
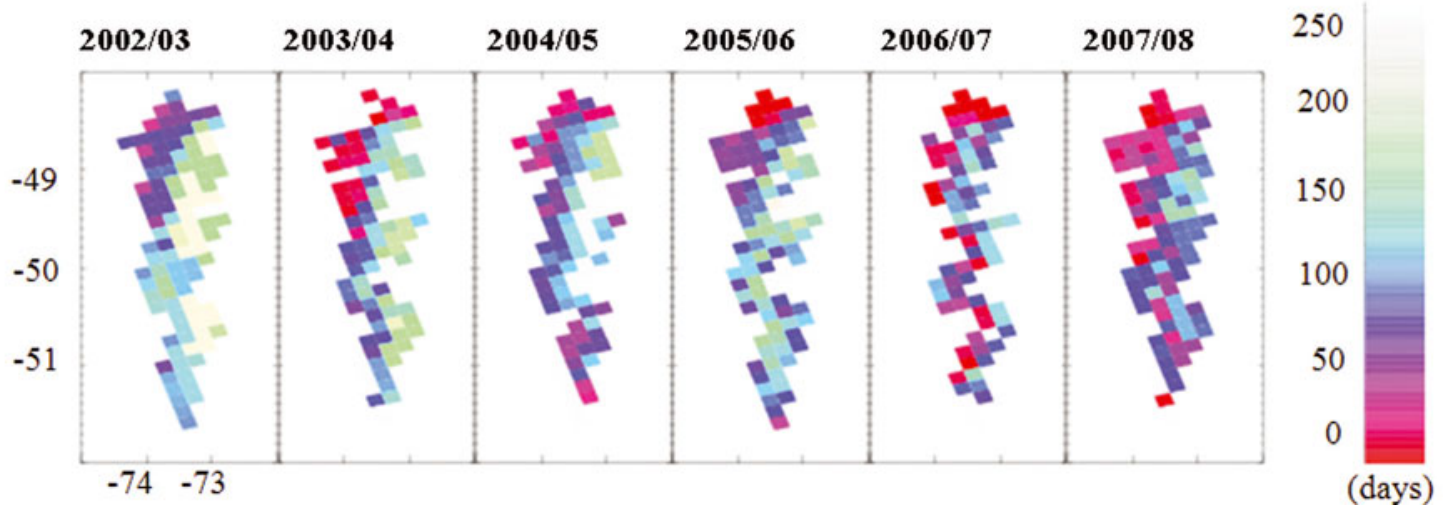

Fig. 8. (a) The mean spring melt-refreeze duration, defined as the difference between the sustained and melt onset dates for all pixels (thick black line) and for pixels with bimodal distributions (thin grey line) for hydrologic years 2002-07. Pixels that have a bimodal distribution with a peak at high $T_{\mathrm{b}}$ are in red, those with a peak at low $T_{\mathrm{b}}$ are in blue, and those with an equal bimodal distribution are in green. (b) Maps showing the spatial and temporal variation of spring melt-refreeze duration for each pixel. These maps demonstrate that the spring meltrefreeze duration (red (0 days) to cyan (150 days) to white (250 days), has shortened regionally from 2002 to 2007.

September, with earlier onsets for pixels west of the divide. Sustained onset starts in September and October in the north and in December and January below $48^{\circ} 50^{\prime} \mathrm{S}$. Pixels west of the divide begin sustained melting 23-35 days earlier.

These melt characteristics can also be interpreted through $T_{\mathrm{b}}$ histogram shapes, which show distinct melt regimes on the windward and leeward side of the Andes. Pixels on the windward side of the Andes have AMSR-E 37V $T_{\mathrm{b}}$ histograms that are asymmetrical in shape, skewed to the right and peak $4-8 \mathrm{~K}$ above $252 \mathrm{~K}$. Even with increases in latitude and elevation, the histograms retain this shape. We interpret this as sites dominated by melt- or rain-induced surface moisture and the region's higher accumulation rate. Pixels on the leeward side have $37 \mathrm{~V} T_{\mathrm{b}}$ histograms with a bimodal distribution. The $252 \mathrm{~K} T_{\mathrm{b}}$ threshold separates the higher cluster of $T_{\mathrm{b}}$, indicative of wet snow, from $T_{\mathrm{b}}$ measurements with $<1 \%$ liquid water content. With increasing elevation, $T_{\mathrm{b}}$ count increases at the lower $T_{\mathrm{b}}$ values. This distribution is typical of other large ice masses such as the icefields of Alaska and Greenland. On the SPI, regions with bimodal peaks at high $T_{\mathrm{b}}$ include northeast and southeast regions where mean elevations are $<1500 \mathrm{~m}$ a.s.l.

For each hydrologic year from 2002 to 2007, the icefield surface is frozen in winter and fall and is wet and melting in summer. In spring the windward side of the Andes is wet and melting while the leeward side remains frozen. In the northwest sector of the SPI $T_{\mathrm{b}}$ 's remain above the threshold from spring to fall, and spend $50 \%$ of the time above $252 \mathrm{~K}$ in winter. The dominant $T_{\mathrm{b}}$ distribution over the SPI shows high-contrast characteristics, with large periods of melt, nonmelt and melt-refreeze cycles within the $T_{\mathrm{b}}$ time series, except in the northwest which has a low-contrast signature, probably dominated by the maritime climate.

For all pixels, the mean spring melt-refreeze period has changed by -10 days $\mathrm{a}^{-1}$, and by -16 days $\mathrm{a}^{-1}$ for pixels with bimodal distributions. The mean spring melt-refreeze period is decreasing for those pixels with bimodal distribution with peaks at low $T_{\mathrm{b}}$ (-22 days $\mathrm{a}^{-1}$ change). Although spatial and 
temporal variability exists, a decreasing duration of the spring melt-refreeze period is apparent from hydrologic years 2002-07.

Melt extent, timing, trends and their relationship to runoff timing and mass balance are significant factors to monitor as the icefields are exposed to a changing climate. Quantifying the influence of the melt on mass balance, runoff and surface-atmosphere interactions aids modeling efforts to calculate the volumetric loss rates for all large temperate glacial systems.

\section{ACKNOWLEDGEMENTS}

We thank Lehigh University and NASA for support that came directly and indirectly from NASA grants NNG04G095G to J. Ramage and NNXO8AI87G to M. Pritchard and J. Ramage. We acknowledge the SRTM digital topographic data from NASA, the SPI coverage using ASTER images from NASA/ National Space Development Agency of Japan (NASDA), and AMSR-E /Aqua L2A Global Swath Spatially Resampled satellite measurements and the Swath-to-Grid Toolkit from the NSIDC. Drainage basin delineations to infer the Andean topographic divide are from the United States Geological Survey. G. Casassa provided the glacier extents. We thank R. Hock, H. De Angelis and an anonymous reviewer for helpful comments on earlier versions of this paper.

\section{REFERENCES}

Abdalati, W. and K. Steffen. 1995. Passive microwave-derived snow melt regions on the Greenland ice sheet. Geophys. Res. Lett., 22(7), 787-790.

Abdalati, W. and K. Steffen. 1997. Snowmelt on the Greenland ice sheet as derived from passive microwave satellite data. J. Climate, 10(2), 165-175.

Aniya, M., H. Sato, R. Naruse, P. Skvarca and G. Casassa. 1997. Recent glacier variations in the Southern Patagonia Icefield, South America. Arct. Alp. Res., 29(1), 1-12.

Apgar, J.D., J.M. Ramage, R.A. McKenney and P. Maltais. 2007. AMSR-E algorithm for snowmelt onset detection in sub-arctic heterogeneous terrain. Hydrol. Process., 21(12), 1587-1596.

Bamber, J.L. and A. Rivera. 2007. A review of remote sensing methods for glacier mass balance determination. Global Planet. Change, 59(1-4), 138-148.

Chang, A.T.C., P. Gloersen, T. Schmugge, T.T. Wilheit and H.J. Zwally. 1976. Microwave emission from snow and glacier ice. J. Glaciol., 16(74), 23-39.

Chen, J.L., C.R. Wilson, B.D. Tapley, D.D. Blankenship and E.R. Ivins. 2007. Patagonia Icefield melting observed by Gravity Recovery and Climate Experiment (GRACE). Geophys. Res. Lett., 43(22), L22501. (10.1029/2007GL031871.)

De Angelis, H., F. Rau and P. Skvarca. 2007. Snow zonation on Hielo Patagónico Sur, Southern Patagonia, derived from Landsat 5 TM data. Global Planet. Change, 59(1-4), 149-158.

Drobot, S.D. and M.R. Anderson. 2001. An improved method for determining snowmelt onset dates over Arctic sea ice using scanning multichannel microwave radiometer and Special Sensor Microwave/Imager data. J. Geophys. Res., 106(D20), 24,033-24,050

Farr, T.G. and M. Kobrick. 2000. Shuttle Radar Topography Mission produces a wealth of data. Eos, 81(48), 583, 585.

Kawanishi, T. and 9 others. 2003. The Advanced Microwave Scanning Radiometer for the Earth Observing System (AMSR-E),
NASDA's contribution to the EOS for global energy and water cycle studies. IEEE Trans. Geosci. Remote Sens., 41(2), 184-194.

Kopczynski, S. and 6 others. 2008. Passive microwave (SSM/I) satellite predictions of valley glacier hydrology, Matanuska Glacier, Alaska. Geophys. Res. Lett., 35(16), L16502. (10.1029/ 2008GL034615.)

Liu, H., L. Wang and K.C. Jezek. 2006. Spatiotemporal variations of snowmelt in Antarctica derived from satellite scanning multichannel microwave radiometer and Special Sensor Microwave Imager data (1978-2004). J. Geophys. Res., 111(F1), F01003. (10.1029/2005JF000318.)

Mote, T.L. 2003. Estimation of runoff rates, mass balance, and elevation changes on the Greenland ice sheet from passive microwave observations. J. Geophys. Res., 108(D2), 4056. (10.1029/2001JD002032.)

Mote, T.L. and M.R. Anderson. 1995. Variations in snowpack melt on the Greenland ice sheet based on passive-microwave measurements. J. Glaciol., 41(137), 51-60.

Mote, T.L., M.R. Anderson, K.C. Kuivinen and C.M. Rowe. 1993. Passive microwave-derived spatial and temporal variations of summer melt on the Greenland ice sheet. Ann. Glaciol., 17, 233-238.

Naruse, R. and M. Aniya. 1992. Outline of glacier research project in Patagonia, 1990. Bull. Glacier Res., 10, 31-38.

Picard, G., M. Fily and H. Gallee. 2007. Surface melting derived from microwave radiometers: a climatic indicator in Antarctica. Ann. Glaciol., 46, 29-34.

Ramage, J.M. 2001. Satellite remote sensing of daily, seasonal, and annual changes on southeast Alaskan glaciers, 1986-1998. (PhD thesis, Cornell University.)

Ramage, J.M. and B.L. Isacks. 2002. Determination of melt-onset and refreeze timing on southeast Alaskan icefields using SSM/I diurnal amplitude variations. Ann. Glaciol., 34, 391-398.

Ramage, J.M. and B.L. Isacks. 2003. Interannual variations of snowmelt and refreeze timing in southeast-Alaskan icefields, U.S.A. J. Glaciol., 49(164), 102-116.

Ramage, J.M., J.D. Apgar, R.A. McKenney and W. Hanna. 2007 Spatial variability of snowmelt timing from AMSR-E and SSM/I passive microwave sensors, Pelly River, Yukon Territory, Canada. Hydrol. Process., 21(12), 1548-1560.

Rasmussen, L.A., H. Conway and C.F. Raymond. 2007. Influence of upper air conditions on the Patagonia icefields. Global Planet. Change, 59(1-4), 203-216.

Rignot, E., A. Rivera and G. Casassa. 2003. Contribution of the Patagonian icefields of South America to sea level rise. Science, 302(5644), 434-437.

Rivera, A. and G. Casassa. 2004. Ice elevation, areal and frontal changes of glaciers from National Park Torres del Paine, Southern Patagonia Icefield. Arct. Antarct. Alp. Res., 36(4), 379-389.

Steffen, K., W. Abdalati and J. Stroeve. 1993. Climate sensitivity studies of the Greenland ice sheet using satellite AVHRR, SMMR, SSM/I and in situ data. Meteorol. Atmos. Phys., 51(3-4), 239-258.

Tedesco, M. 2007. Snowmelt detection over the Greenland ice sheet from SSM/I brightness temperature daily variations. Geophys. Res. Lett., 34(2), L02504. (10.1029/2006GL028466.)

Ulaby, F.T., R.K. Moore and A.K. Fung. 1986. Microwave remote sensing, active and passive. Vol. 3. From theory to applications. Reading, MA, Addison-Wesley.

Warren, C.R. and D.E. Sugden. 1993. The Patagonian icefields: a glaciological review. Arct. Alp. Res., 25(4), 316-331.

Zwally, H.J. and S. Fiegles. 1994. Extent and duration of Antarctic surface melting. J. Glaciol., 40(136), 463-476.

Zwally, H.J., W. Abdalati, T. Herring, K. Larson, J. Saba and K. Steffen. 2002. Surface melt-induced acceleration of Greenland ice-sheet flow. Science, 297(5579), 218-222. 